\title{
MACULAR AND PERIPAPILLARY RETINAL NERVE FIBER THICKNESS IN UNILATERAL AMBLYOPIC EYE
}

\author{
Chunu Shrestha, Reeta Rajbhandari and Manish Poudel
}

Eye See You Eye Care Centre, Rabi Bhawan, Kathmandu, Nepal

\begin{abstract}
Amblyopia is the most common cause of monocular visual impairment in both children, and young to middle-aged adults, affecting $2 \%-5 \%$ of the general population. The objective of this study was to compare the peripapillary nerve fiber thickness and macular thickness in amblyopic eyes, fellow eyes and normal control eyes using spectral domain optical coherence tomography. This was a cross-sectional observational study conducted at R M Kedia Eye Hospital, Birgunj, Nepal from February 2020 to July 2020. Pediatric patients with unilateral amblyopia (anisometropic amblyopia, strabismic amblyopia or both) among the age group of 6-18 years attending pediatric department of RM Kedia Eye Hospital were enrolled for the study. All patients underwent a full ophthalmological assessment, including visual-acuity testing, anterior segment evaluation with Topcon slit lamp and fundus examination with Volk +90D lenses. All statistical analysis was done in SPSS V. 20. The average peripapillary retinal nerve fiber layer thickness was 120.6 $\mu \mathrm{m}(\mathrm{SD}=14.6 \mu \mathrm{m})$ in the amblyopic eye, $118.1 \mu \mathrm{m}(\mathrm{SD}=15.6 \mu \mathrm{m})$ in the fellow eye and $113.2 \mu \mathrm{m}$ $(\mathrm{SD}=9.4 \mu \mathrm{m})$ in the normal eye $(\mathrm{p}=0.104)$ respectively. The average macular thickness was 298.6 $\mu \mathrm{m}(\mathrm{SD}=19.1 \mu \mathrm{m})$ in the amblyopic eye, $296.9 \mu \mathrm{m}(\mathrm{SD}=11.2 \mu \mathrm{m})$ in the fellow eye and $303 \mu \mathrm{m}$ $(\mathrm{SD}=12.4 \mu \mathrm{m})$ in the normal eye $(\mathrm{p}=0.260)$ respectively. In conclusion, our study did not find any significant difference in the peripapillary retinal nerve fiber thickness or macular thickness when compared between amblyopic eyes, fellow eyes, gender and age matched normal eyes.
\end{abstract}

\section{KEYWORDS}

Amblyopia, spectral domain OCT,

Retinal nerve fiber thickness, macular thickness

Received on: January 20, 2021

Accepted for publication: March 03, 2021

\section{CORRESPONDING AUTHOR}

Dr. Chunu Shrestha,

Phaco and Retina Surgeon,

Eye See You Eye Care Centre, Rabi Bhawan,

Kathmandu, Nepal

Email: chunu20@hotmail.com

Orcid No: https://orcid.org/0000-0002-7663-8292

DOI: https://doi.org/10.3126/nmcj.v23i2.38522 


\section{INTRODUCTION}

Amblyopia is a deficiency of form sense resulting in the reduction in visual acuity of greater than two lines between the eyes or an absolute reduction in acuity below 6/9 in either eye, associated with decrements in visual processing, accommodation, motility, spatial perception or spatial projection. ${ }^{2}$ It is the most common cause of monocular visual impairment in both children, and young to middle-aged adults, affecting $2-5 \%$ of the general population. ${ }^{1}$

The types of amblyopia in frequency is strabismus (about 50\%), usually esotropia in infancy or early childhood. The second type is anisometropia (approx. 17\%), followed by a combination of strabismus and anisometropia (about 30\%), and finally the least frequent cause is visual deprivation $(\leq 3 \%)$ although this one may result in severe amblyopia. ${ }^{3}$

Yen et $a l^{4}$ has hypothesized that there is a measurable increase in retinal nerve fiber layer thickness in amblyopic eyes as amblyopia may affect the postnatal maturation of the retina, including the postnatal reduction of ganglion cells.

Although most of the deficit is believed to be the result of impairment of cortical development, changes have been seen in the lateral geniculate nucleus of nonhuman primates and humans after visual deprivation amblyopia during the neonatal period. ${ }^{5,6}$

Some eyes diagnosed with amblyopia may also have abnormalities in the afferent visual system anterior to the striate cortex, including the retina, retinal ganglion cell, retinal nerve fiber layer (RNFL), optic nerve, and lateral geniculate body of the thalamus. ${ }^{7}$

Optical coherence tomography (OCT) of the peripapillary optic nerve is a non-invasive test in which the thickness of the RNFL is measured. RNFL thickness correlates with disc area in children. ${ }^{8}$

OCT has been used to compare the RNFL of amblyopic and fellow eyes of patients of varied ages. ${ }^{4,9}$ One study found a small statistically significant difference between eyes for anisometropic amblyopia and no difference for strabismic amblyopia. ${ }^{4}$ Another study found no difference but had insufficient numbers to evaluate subgroups by cause. ${ }^{9}$

Spectral-domain OCT (SD-OCT) (also called Fourier-domain OCT) is a new-generation OCT technology that can provide ultrahigh image resolution at an ultrahigh rate. As distinct from the first-generation TD-OCT, SD-OCT uses a spectrometer instead of a photodetector. The depth data are obtained by analyzing the interference pattern, which is formed in the spectrum of the rays reflected from the ocular tissues. Then, the data from the spectrometer are exposed to the Fourier transformation to generate a 3-dimensional image. ${ }^{10-14}$

SD-OCT measurements of macular thickness and volume as well as peripapillary RNFL thickness in children was first reported by Turk et al. ${ }^{15}$

In Nepal, comparison between the OCT findings and amblyopia has not been reported till date. Hence this study will provide a baseline report of peripapillary retinal nerve fiber layer thickness and macular thickness in amblyopic patients.

\section{MATERIALS AND METHODS}

This was a comparative cross-sectional observational study conducted at R M Kedia Eye Hospital, Birgunj, Nepal from February 2020 to July 2020. All cases of pediatric amblyopia were included in the study. Fellow eyes and normal eyes were taken for comparison with affected eyes. Ethical clearance letter was taken from Nepal Health Research Council. Written informed consent was obtained from parents/ guardians of each participating minors. Amblyopia was defined as a deficiency of form sense resulting in the reduction in visual acuity of greater than two lines between the eyes or an absolute reduction in acuity below 6/9 either eye, associated with decrements in visual processing, accommodation, motility, spatial perception or spatial projection. Unilateral amblyopia was defined as BCVA of 6/9 in either eye or as an interocular difference of two lines or more. Severe amblyopia was defined as BCVA of $<6 / 36$, moderate amblyopia as BCVA of $<6 / 12$ to $6 / 36$ and mild amblyopia as BCVA of $6 / 9$ to $6 / 12$. Anisometropia was defined as refractive difference of $>1.50 \mathrm{D}$ between the eyes.

Pediatric patients with unilateral amblyopia (anisometropic amblyopia, strabismic amblyopia or both) among the age group of 6-18 years attending pediatric department of RM Kedia Eye Hospital were enrolled for the study.

Inclusion criteria included children born at term ( $\geq 37$ weeks gestational age), with normal birth weight $(\geq 2500 \mathrm{~g})$ with best-corrected visual acuity over 0.8 (on the Snellen scale) for both eyes with refractive error (in spherical 
equivalent) within \pm 5.00 diopters, intraocular pressure $\leq 21 \mathrm{~mm} \mathrm{Hg}$ in eyes, cup-to-disc (C/D) ratio $\leq 0.4$ and C/D ratio asymmetry $\leq 0.2$ between the 2 eyes without any retinal or optic disc anomaly. Patients with neurological diseases, ocular conditions such as glaucoma, retinal disorders and nystagmus, patients not cooperating for SD-OCT examination and patients not providing consent were excluded.

All patients underwent a full ophthalmological assessment, including visual-acuity testing with tumbling E chart, evaluation of ocular alignment, anterior segment examination with Topcon slit lamp and fundus examination with Volk +90D lens after dilatation of pupil. The Best corrected visual acuity was transformed to a logarithmic scale (logMAR) for statistical analysis. Cycloplegic refraction was performed using retinoscopy $60 \mathrm{~min}$ after the instillation of $1 \%$ cyclopentolate and $0.5 \%$ tropicamide. The best corrected visual acuity was converted to logarithmic scale (LogMAR) for statistical analysis. Cycloplegic refraction was performed using retinoscopy 60 minutes after the instillation of $1 \%$ cyclopentolate and $0.5 \%$ tropicamide. Axial length measurement (Nidek ECHO SCAN US 800) and intraocular pressure measurement (using Applanation tonometer in cooperative patients) were conducted.

The Spectralis OCT device (Heidelberg Engineering, Dossenheim, Germany were used for the SD-OCT assessment and were performed by the same experienced technician in the dilated pupil. The macula and peripapillary RNFL thickness was analyzed and automatically calculated by SD-OCT device. A fast macular map scan protocol was used to scan the macular thickness. It consisted of 6 consecutive $6-\mathrm{mm}$ radial scans centered on the fovea with each scan 30 degree apart around the fovea. Data for macular retinal thickness were displayed in 3 concentric circles, with radii of $1 \mathrm{~mm}$ (foveal central), $3 \mathrm{~mm}$ (inner circle), and $6 \mathrm{~mm}$ (outer circle). Retinal thickness was defined as the distance between the reflection at the vitreoretinal interface and the anterior boundary of the reflective layer corresponding to the retinal pigment epithelium and choriocapillaris. The macular thickness parameters were divided into central (1 $\mathrm{mm})$, inner circle $(3 \mathrm{~mm})$, outer circle $(6$ $\mathrm{mm}$ ), and average thickness. The peripapillary RNFL thickness parameters were divided into temporal quadrant thickness (90 degrees), temporal superior quadrant thickness (45 degrees), temporal inferior quadrant thickness (45 degrees), nasal quadrant thickness (90 degrees), nasal superior quadrant thickness (45 degrees), nasal inferior quadrant thickness (45 degrees), and average thickness (360 degrees). After the exposures, the non-centered scans and the scans with signal strength $<15 \mathrm{~dB}$ were excluded from the study.

The results obtained from the SD-OCT were expressed as mean +/- standard deviation. Visual acuity data were converted to logarithms of the minimal angle of resolution (logMAR) for statistical calculation and analysis.

Data was entered in MS Excel. All statistical analysis was done in SPSS V. 20. Descriptive statistics such as frequencies, percentages Mean (SD) etc were determined. For the independent continuous variable, if the data followed normality assumption independent $t$ test was used and if the data did not follow normality assumption Mann Whitney $U$ test was used. P-value <0.05 was considered as statistically significant.

\section{RESULTS}

Thirty amblyopic patients $(23,76.7 \%$ males and $7,23.3 \%$ females) were recruited in the study with average \pm SD age of $14.0 \pm 3.1$ (range: 6-18) years. Twenty patients (66.7\%) had anisometropic amblyopia, 4 (13.3\%) had strabismic amblyopia and 6 (20\%) had a mixedtype amblyopia. Out of twenty anisometropic amblyopia patients, 17 (85.0\%) had hypermetropic anisometropia and 3 (15.0\%) had myopic anisometropia. Fifteen patients (50\%) had severe amblyopia, 13 (43.3\%) had moderate amblyopia and $2(6.7 \%)$ had mild amblyopia.

Fellow eyes and normal eyes were also taken for comparison with affected eyes. There were no statistically significant difference in between right and left eyes of normal participants in terms of visual acuity $(\mathrm{p}=0.841)$, axial length $(p=0.981)$, macula average $(p=0.916)$ and RNFL thickness $(p=0.676)$. Thirty normal eyes (23 male eyes, 7 female eyes) were selected randomly

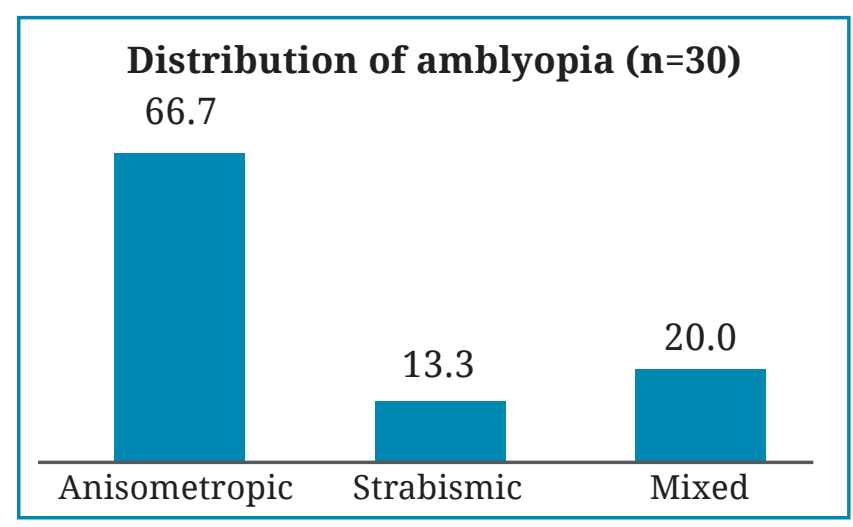

Fig. 1: Distribution of Amblyopia 
Table 1: Topographical measurements of amblyopic eyes, fellow eyes and normal eyes.

\begin{tabular}{|c|c|c|c|c|c|c|c|c|}
\hline & & Affected Eye & Fellow Eye & Normal & $\begin{array}{l}\text { Overall } \\
\text { P value }\end{array}$ & $\begin{array}{l}\text { Ae vs FE } \\
P \text { value }\end{array}$ & $\begin{array}{l}N \text { vs } A E \\
P \text { value }\end{array}$ & $\begin{array}{l}\mathrm{N} \text { vs } \mathrm{FE} \\
\mathrm{P} \text { value }\end{array}$ \\
\hline $\begin{array}{l}\text { LOGMAR } \\
\mathrm{AE}\end{array}$ & $\begin{array}{l}\text { Median } \\
\text { (Range) }\end{array}$ & $1.3(0.6-1.8)$ & $0(0-0.8)$ & $0(0-2)$ & $<0.001$ & $<0.001$ & $<0.001$ & .299 \\
\hline SE & $\begin{array}{l}\text { Median } \\
\text { (Range) }\end{array}$ & $4(-4-4)$ & $0(-1-1.3)$ & $0(-2.8-0)$ & $<0.001$ & $<0.001$ & $<0.001$ & .002 \\
\hline $\begin{array}{l}\text { AXIAL } \\
\text { LENGTH }\end{array}$ & $\begin{array}{l}\text { Mean } \\
\text { (SD) }\end{array}$ & $21.6(1.3)$ & 22.7 (1.1) & $23.5(1)$ & $<0.001$ & .002 & $<0.001$ & .021 \\
\hline M-Average & $\begin{array}{l}\text { Mean } \\
\text { (SD) }\end{array}$ & $298.6(19.1)$ & $296.9(11.2)$ & 303 (12.4) & .260 & 1.000 & .751 & .338 \\
\hline SN & $\begin{array}{l}\text { Mean } \\
\text { (SD) }\end{array}$ & $139.3(25)$ & $126.9(36.6)$ & $124(27.6)$ & .121 & .347 & .161 & 1.000 \\
\hline ST & $\begin{array}{l}\text { Mean } \\
\text { (SD) }\end{array}$ & $136.8(20.4)$ & $150.5(23.5)$ & $141.1(22)$ & .052 & .053 & 1.000 & .300 \\
\hline IN & $\begin{array}{l}\text { Mean } \\
\text { (SD) }\end{array}$ & $136.1(23.3)$ & $127.5(31.7)$ & 113.3 (17.9) & .003 & .561 & .002 & .090 \\
\hline IT & $\begin{array}{l}\text { Mean } \\
\text { (SD) }\end{array}$ & $152(25.8)$ & $148.1(31.4)$ & $153.2(25)$ & .757 & 1.000 & 1.000 & 1.000 \\
\hline $\mathrm{T}$ & $\begin{array}{l}\text { Mean } \\
\text { (SD) }\end{array}$ & 71.5 (11.4) & 76.3 (12.5) & $75.2(14.8)$ & .324 & .457 & .816 & 1.000 \\
\hline $\mathrm{N}$ & $\begin{array}{l}\text { Mean } \\
\text { (SD) }\end{array}$ & 87.7 (17.6) & $79(20.6)$ & 72.4 (16.7) & .007 & .206 & .005 & .496 \\
\hline $\begin{array}{l}\text { M-RNFL- } \\
\text { Average }\end{array}$ & $\begin{array}{l}\text { Mean } \\
\text { (SD) }\end{array}$ & $120.6(14.6)$ & $118.1(15.6)$ & $113.2(9.4)$ & .104 & 1.000 & .111 & .496 \\
\hline
\end{tabular}

to match the distribution of gender and age of the affected eye for better comparison. The average \pm SD age of normal group was $14.0 \pm 3.1$ (range: 6-18) years which was not statistically significant with mean age of participants of the affected eye $(p=0.71)$.

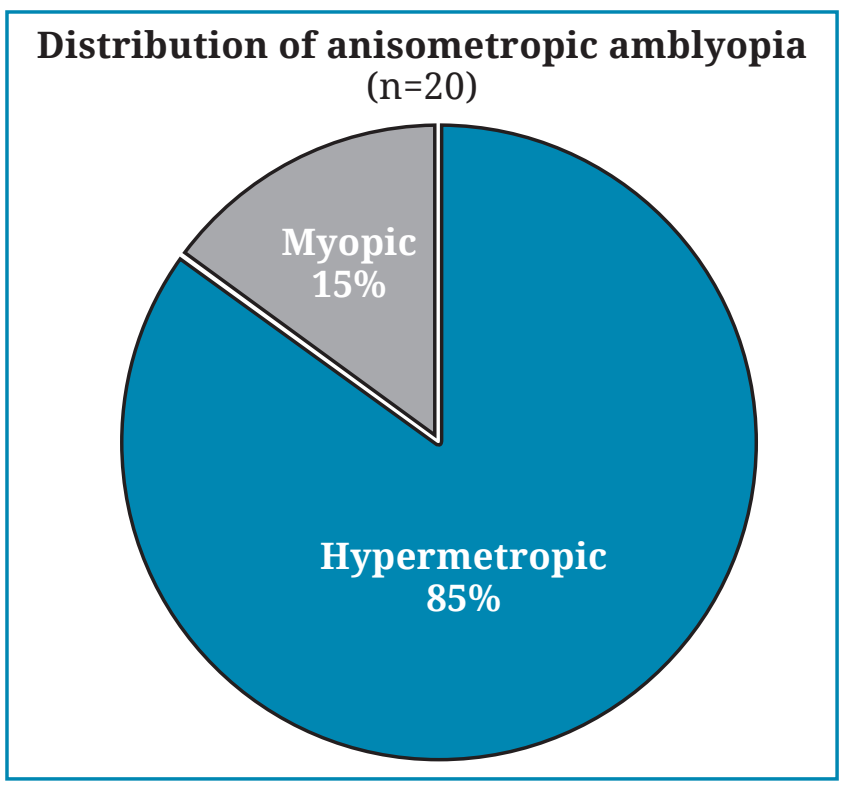

Fig. 2: Distribution of anisometropic amblyopia
Visual acuity in amblyopia ranged from LogMAR 0.6 to 1.8 (median=1.3), in fellow eye ranged from LogMAR 0.0 to 0.8 (median=0.0) and in normal group ranged from LogMAR 0.0 to 2 (median=0.0) $(\mathrm{p}<0.001)$.

The median (range) spherical equivalent was 4D (-4 to 4) in amblyopic eyes, 0D (-1 to 1.3$)$ in fellow eyes and 0D ( -0.2 to 0$)$ in normal eyes, $\mathrm{p}<0.001$.

The average peripapillary RNFL thickness was $120.6 \mu \mathrm{m}(\mathrm{SD}=14.6 \mu \mathrm{m})$ in the amblyopic eye, $118.1 \mu \mathrm{m}(\mathrm{SD}=15.6 \mu \mathrm{m})$ in the fellow eye and $113.2 \mu \mathrm{m}(\mathrm{SD}=9.4 \mu \mathrm{m})$ in the normal eye $(p=0.104)$.

In anisometropic amblyopia, the average peripapillary RNFL thickness was $120.9 \mu \mathrm{m}$ $(\mathrm{SD}=13.6 \mu \mathrm{m})$ in the amblyopic eye and $115.8 \mu \mathrm{m}$ $(\mathrm{SD}=12.3 \mu \mathrm{m})$ in the normal eye $(p=0.219)$. Superonasal (SN) and Inferonasal (IN) quadrant was thicker in anisometropic eye in comparison with normal eyes which was statistically significant ( $\mathrm{p}$ value $\mathrm{SN}=0.22, \mathrm{IN}=0.003$ )

The average macular thickness was $298.6 \mu \mathrm{m}$ $(\mathrm{SD}=19.1 \mu \mathrm{m})$ in the amblyopic eye, $296.9 \mu \mathrm{m}$ $(\mathrm{SD}=11.2 \mu \mathrm{m})$ in the fellow eye and $303 \mu \mathrm{m}$ $(\mathrm{SD}=12.4 \mu \mathrm{m})$ in the normal eye $(p=0.260)$. 


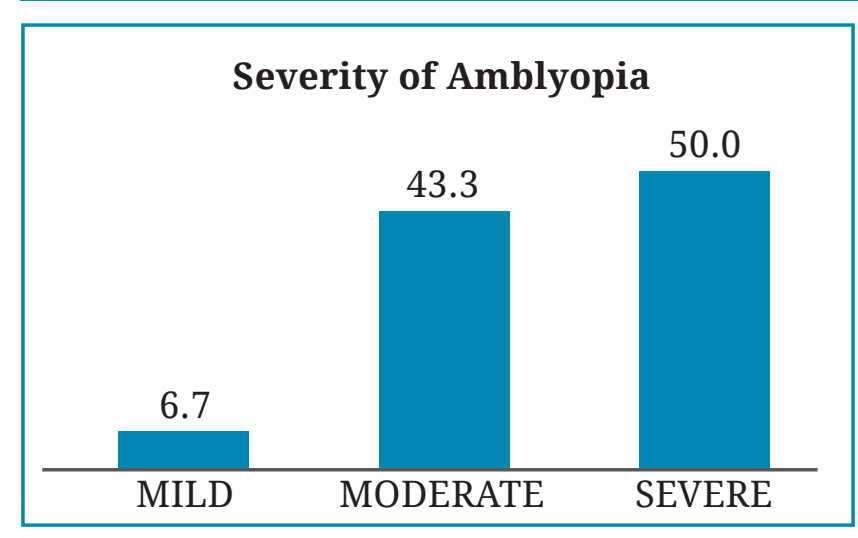

Fig. 3: Severity of amblyopia

Regarding anisometropic amblyopia, the values for the amblyopic and normal eyes were $301.7 \mu \mathrm{m}(\mathrm{SD}=17 \mu \mathrm{m})$ and $304.3 \mu \mathrm{m}(\mathrm{SD} 12 \mu \mathrm{m})$ $(p=0.575)$ respectively. The average macular thickness was $298.6 \mu \mathrm{m}(\mathrm{SD}=19.1 \mu \mathrm{m})$ in the amblyopic eyes, $296.9 \mu \mathrm{m}(\mathrm{SD}=11.2 \mu \mathrm{m})$ in the fellow eyes and $303 \mu \mathrm{m}(\mathrm{SD}=12.4 \mu \mathrm{m})$ in the normal eyes $(p=0.260)$.

\section{DISCUSSION}

Our study did not find any difference in either peripapillary RNFL thickness or macular thickness when compared between the amblyopic eye and fellow eyes; and also between amblyopic eyes and normal control eyes. The patients presented with anisometropic, strabismic and mixed type of amblyopia and no significant difference between macular thickness and peripapillary RNFL thickness was observed between all these types of amblyopia.

Repka et $a l^{9}$ compared the peripapillary RNFL thickness of sound and amblyopic eyes in a prospective observational case series. Both eyes of seventeen patients (mean age 10.7 years) were imaged. The mean thickness of the sound eye was $109.2 \mu \mathrm{m}$ (median 112.7) and of the amblyopic eye was $104.2 \mu$ m (median 105.0), and the average difference (sound eye less amblyopic eye) was $5.0 \mu \mathrm{m}$ (median 3.0) (95\% confidence interval $-2.3,12.2, P=.17$ ). The difference in nerve fiber layer (NFL) thickness between amblyopic and sound eyes was clinically non-significant like in our study.

Huynh et $a l^{16}$ examined macular and peripapillary retinal nerve fiber layer (RNFL) thickness in amblyopia of 4118 children in the Sydney Childhood Eye Study. Amblyopic eyes had slightly greater foveal minimum thickness than the normal fellow eye (by $5.0 \mu \mathrm{m} ; 95 \%$ confidence interval 0.1-9.9) with $\mathrm{P}<0.05$. This was more pronounced in 6-year-old children (6.9 $\mu \mathrm{m})$. Amblyopic eyes also had slightly thicker central macula (1 $\mathrm{mm}$ diameter region) but was not statistically significant. Peripapillary RNFL thickness was not significantly different between amblyopic and normal fellow eyes or normal eyes of non-amblyopic children similar to our study.

Altintas et al, ${ }^{17}$ found no significant differences while comparing the thickness of the RNFL, the macular volume, and the macular thickness of the amblyopic eye with those of the nonamblyopic eye in patients with unilateral strabismic amblyopia using optical coherence tomography (OCT). The mean age was 10.43 years $(+/-4.09$ years $)$.

Dickmann et at. ${ }^{18}$ examined 30 consecutive patients with spectral domain optical coherence tomography to determine the difference in the retinal nerve fiber layer thickness (RNFLT), macular thickness (MT), and foveal volume (FV) among the amblyopic and the fellow eyes in patients with unilateral amblyopia. There were no significant differences between the amblyopic and sound eyes in FV, MT, and RNFLT.

Repka et $a l^{19}$ compared the peripapillary RNFL thickness of amblyopic and fellow eyes of 37 patients between the age of 7 to 12 years with unilateral strabismic, anisometropic, or combined-mechanism amblyopia in 2009. The mean global RNFL thickness of the amblyopic and fellow eyes was $111.4 \mu \mathrm{m}$ and $109.6 \mu \mathrm{m}$ respectively. No significant difference was found between the amblyopic and fellow eye which is similar to our study.

Kee et $a l^{20}$ studied 52 eyes of 26 children with unilateral amblyopia (anisometropia or strabismus) and compared it with fellow eyes and normal eyes. No difference was seen in peripapillary and macular thickness between the amblyopic eye and fellow eye, nor between amblyopic eyes and normal control group.

Yoon et $a l^{21}$ assessed OCT of 31 patients with hyperopic anisometropic amblyopia. It showed significantly thicker RNFL in amblyopic patients $(\mathrm{P}=0.019)$, but no statistically significant difference was found in macular retinal thickness $(\mathrm{P}>0.05)$.

In a study by Demircan et $a l^{22}$ mean central macular thickness in the hyperopic anisometropic amblyopic eyes was found to be significantly thicker $(P=.001)$ in the group aged 5 to 12 years; but not in case of group aged 13 to 42 years. There was no significant difference in average RNFL thickness in either group.

In our study no significant difference is seen in either macular thickness $(\mathrm{P}=0.22)$ 
or peripapillary RNFL thickness $(\mathrm{P}=0.084)$ among patients with hyperopic anisometropic amblyopia when compared with normal eyes which is similar to many other studies..$^{23,24}$

The peripapillary RNFL thickness in the fellow eye in the current study is $118.1 \mu \mathrm{m}$ which is similar to the normative data reported by Salchow ${ }^{25}$ and associates among similarly aged children, supporting our use of the fellow eye as an appropriate comparison.

Strength of the study is sample size, detailed ocular examination and equal distribution of age and gender of patient between amblyopic and normal group.

The limitation of this study is that the patients enrolled had different types of amblyopia including $66.7 \%$ anisometropic amblyopia, $13.3 \%$ strabismic amblyopia and $20 \%$ mixedtype of amblyopia, so the results cannot be generalized to those with deprivational amblyopia.

In conclusion, our study did not find any significant difference in the peripapillary retinal nerve fiber thickness or macular thickness when compared between amblyopic eyes, fellow eyes, gender and age matched normal eyes. This study also helps to determine the baseline peripapillary retinal nerve fiber thickness and macular thickness among amblyopic and normal pediatric patients in Nepal. Future studies involving pediatric patients with equal number of different types of amblyopic may help to generalize the result in deprivational amblyopia.

\section{ACKNOWLEDGEMENTS}

We are greatly indebted to the children and their parents for being part of this study and for their valuable time and co-operation.

\section{Source of Research Fund: None}

\section{Conflict of Interest: None}

\section{REFERENCES}

1. Gopal SKS, Kelkar J, Kelkar A, Pandit A. Simplified updates on the pathophysiology and recent developments in the treatment of amblyopia: A review. Indian J Ophthalmol 2019; 67:13921399.

2. Gupta AK, Krishna V. Contemporary perspective on Ophthalmology. India: Elsevier, a division of Reed Elsevier India Private Limited; 2006.
3. Hillis A, Flynn JT, Hawkins BS. The evolving concept of amblyopia: a challenge to epidemiologists. Am J Epidemiol 1983; 118: 192205.

4. Yen MY, Cheng CY, Wang AG. Retinal nerve fiber layer thickness in unilateral amblyopia. Invest Ophthalmol Vis Sci 2004; 45: 2224-30.

5. Von Noorden GK, Middleditch PR. Histology of the monkey lateral geniculate nucleus after unilateral lid closure and experimental strabismus: further observations. Invest Ophthalmol 1975; 14: 674-83.

6. Von Noorden GK, Crawford ML. The lateral geniculate nucleus in human strabismic amblyopia. Invest Ophthalmol Vis Sci 1992; 33: 2729-32.

7. Lempert P. Optic nerve hypoplasia and small eyes in presumed amblyopia. J Amer Assoc Pediatr Ophthalmol Strabismus 2000; 4: 258-66.

8. Huynh SC,Wang XY, Rochthina E, Crowston JG, Mitchell P. Distribution of optic disc parameters measured by OCT: findings from a populationbased study of 6 years old Australian children. Invest Ophthalmol Vis Sci 2006; 47: 3276-85.

9. Repka MX, Coldenberg-Cohen N, Edwards AR. Retinal nerve fiber layer thickness in amblyopic eyes. Am J Ophthalmol 2006; 142: 247-51.

10. Chen TC, Zeng A, Sun W, Mujat M, de Boer JF. Spectral domain optical coherence tomography and glaucoma. Int'l Ophthalmol Clin 2008 Fall; 48: 29-45.

11. Wojtkowski M, Leitgeb R, Kowalczyk A, Bajraszewski T, Fercher AF. In vivo human retinal imaging by Fourier domain optical coherence tomography. J Biomed Opt 2002; 7: 457-63.

12. Sakata LM, Deleon-Ortega J, Sakata V, Girkin CA. Optical coherence tomography of the retina and optic nerve - a review. Clin Exp Ophthalmol 2009; 37: 90-9.

13. Chen TC, Cense B, Pierce MC, et al. Spectral domain optical coherence tomography: ultrahigh speed, ultra-high resolution ophthalmic imaging. Arch Ophthalmol 2005; 123: 1715-20.

14. Loduca AL, Zhang C, Zelkha R, Shahidi M. Thickness mapping of retinal layers by spectraldomain optical coherence tomography. Amer J Ophthalmol 2010; 150: 849-55.

15. Turk A, Ceylan OM, Arici C, et al. Evaluation of the nerve fiber layer and macula in the eyes of healthy children using spectral-domain optical coherence tomography. Amer J Ophthalmol 2012; 153: 552-9.

16. Huynh SC, Samarawickrama C, Wang XY, et al. Macular and nerve fiber layer thickness in amblyopia: the Sydney Childhood Eye Study. Ophthalmol 2009; 116: 1604-9.

17. Altintas O, Yüksel N, Ozkan B, Caglar Y. Thickness of the retinal nerve fiber layer, macular thickness, and macular volume in patients with strabismic amblyopia. J Pediatr Ophthalmol Strabismus 2005; 42: 216-21.

18. Dickmann A, Petroni S, Perrotta V, Parrilla R, Aliberti S, Salerni A, Savastano MC. Measurement 
of retinal nerve fiber layer thickness, macular thickness, and foveal volume in amblyopic eyes using spectral-domain optical coherence tomography. J AAPOS 2012; 16: 86-8.

19. Repka MX, Kraker RT, Tamkins SM, et al. Retinal nerve fiber layer thickness in amblyopic eyes. Amer J Ophthalmol 2009; 148: 143-7.

20. Kee SY, Lee SY, Lee YC. Thickness of the fovea and retinal nerve fiber layer in amblyopic and normal eyes in children. Korean J Ophthalmol 2006; 20: 177-81.

21. Yoon SW, Park WH, Baek SH, Kong SM. Thicknesses of macular retinal layer and peripapillary retinal nerve fiber layer in patients with hyperopic anisometropic amblyopia. Korean J Ophthalmol 2005; 19: 62-7.

22. Demircan S, Gokce G, Yuvaci I, Ataş M, Başkan B, Zararsiz G. The assessment of anterior and posterior ocular structures in hyperopic anisometropic amblyopia. Med Sci Monit 2015; 25; 21: 1181-8.

23. Wang BZ, Taranath D: A comparison between the amblyopic eye and normal fellow eye ocular architecture in children with hyperopic anisometropic amblyopia. J AAPOS 2012; 16: 428-30.

24. Firat PG, Ozsoy E. Demirel S et al. Evaluation of peripapillary retinal nerve fiber layer, macula and ganglion cell thickness in amblyopia using spectral optical coherence tomography. Int'l J Ophthalmol 2013; 6: 90-4.

25. Salchow DJ, Oleynikov YS, Chiang MF, KennedySalchow SE, Langton K, Tsai JC, Al-Aswad LA. Retinal nerve fiber layer thickness in normal children measured with optical coherence tomography. Ophthalmology 2006; 113: 786-91. 